Thorax (1954), 9, 175.

\title{
ANATOMY OF THE CRURA OF THE DIAPHRAGM AND THE SURGERY OF HIATUS HERNIA
}

\author{
BY \\ J. LEIGH COLLIS, T. D. KELLY, AND A. M. WILEY
From the Queen Eiizabeth Hospital, Birmingham
}

(RECEIVED FOR PUBLICATION JULY 3, 1954)

\begin{abstract}
PART 1: A NATOM Y
The aim of this work was to improve operative technique in the control of gastric reflux in hiatus hernia by more exact anatomical knowledge. During dissections to establish the nerve supply of the crura (Collis, Satchwell, and Abrams, 1954) it became obvious that there were points in the anatomy of the area which had not been fully described and were not generally appreciated. It seemed reasonable to presume that the anatomical arrangements were designed for a functional result and that deductions could be made from this study about the mechanism of the oesophageal hiatus.
\end{abstract}

\section{MATERIAL}

In preparing the previous paper on the nerve supply of the diaphragm, 14 dissections were made and to this number a further 50 specimens were added for this survey. To estimate percentage frequency of various arrangements this new block of 50 dissections was used because of the ease of the calculations. For dissection wire frames were made, which consisted of two concentric rings of strong copper wire braced by radial supports of the same material. The fresh specimens were attached to these and fixed in formalin before dissection.

\section{Standard Anatomical Pattern}

The considerable number of major points of difference between specimens resulted in only $46 \%$ of cases presenting a standard pattern. This type is in general accord with the text-book description which is so largely based on the short but thorough picture given by Low in 1907 .

Figs. 1, 2, 3, 4, 5 and 6 show the anatomical relations in this group. There is a large right crus and a smaller left crus which takes no part in the formation of the oesophageal hiatus.

The fibres of the right crus arise from the main tendon and in varying degree from the median arcuate ligament. Some of these fibres may arise from this latter ligament to the left of the mid-line (see Figs. 5 and 6), but in all cases they can readily be separated from the left crural fibres.

There is no decussation of muscle fibres in front or behind the oesophageal orifice, but varying degrees of muscle overlap are a constant feature. The fibres on the extreme left of the right crus, which often arise from the median arcuate ligament, pass upwards below the other fibres and cross over to form the right margin of the hiatus. Conversely, fibres from the right side of the right crus pass upwards above the fibres already mentioned to reach the left side of the hiatus. This produces an effect of a doublebreasted coat, more or less well marked from case to case, as shown by comparison of Figs. 1 and 3. When the cross-over effect is well marked it is referred to here as a case with good overlap.

In the standard type the median arcuate ligament is always present, although in many cases it is poorly developed $(36 \%)$.

\section{SHIFT TO THE LEFT}

The fibres forming the right aspect of the oesophageal orifice often arise to the left side of the mid-line. When this only represented a spread of the origin of the right crus across the median arcuate ligament, the specimen was still considered to be of standard type. This group does represent a shift to the left of minor degree and is spoken of as a stage 1 shift. It is shown in Figs. 5 and 6 . Other cases are not uncommon $(34 \%)$, in which a more marked " shift to the left " is present, and, in these, fibres belonging to the left crus take part in the right side of the oesophageal orifice. This point is at direct variance with the standard description.

The shading off to the left with definite participation of the left crus in the right side of the oesophageal hiatus is termed a " stage-2 shift" and occurred in $32 \%$ of cases. A marked example of this is shown in Fig. 7. The overlap below the hiatus presents the usual pattern, but all the fibres forming the lower muscle band come from the left crus. They cross over in a scissor-like fashion, a similar band coming 
A. ORIFICE FOR INFERIOR VENA CAVA

B. OVERLAPPING FIBRES OF RT. CRUS

C. RT. CRUS

D. LT. CRUS

E. MEDIAN ARCUATE LIGAMENT

O. OESOPHAGEAL ORIFICE

Fig. I
FIG. 1.-Standard type of muscular arrangements at the oesophageal hiatus seen from the inferior surface. The quality of muscle is good, with a
good overlap of the fibres from the right across to the left. The fibres pass inferiorly to the similar band passing from the left to the right. A good median arcuate is present. The fibres of the left crus take no part in the boundaries of the oesophageal orifice.

FIG. 2.-Standard type seen from above. Good musculature and strong crossover fibres are seen.

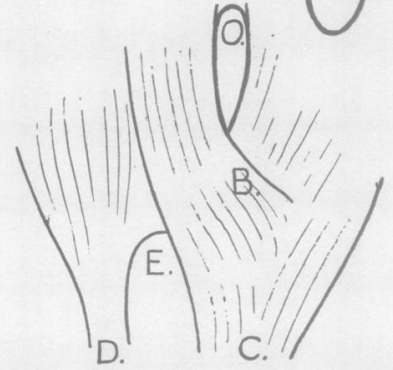

A. ORIFICE FOR INFERIOR VENA CAVA

B. OVERLAPPING FIBRES OF RT. CRUS

C. RT. CRUS

D. LT. CRUS

E. MEDIAN ARCUATE LIGA MENT

O. OESOPHAGEAL ORIFICE

Fig. 2 

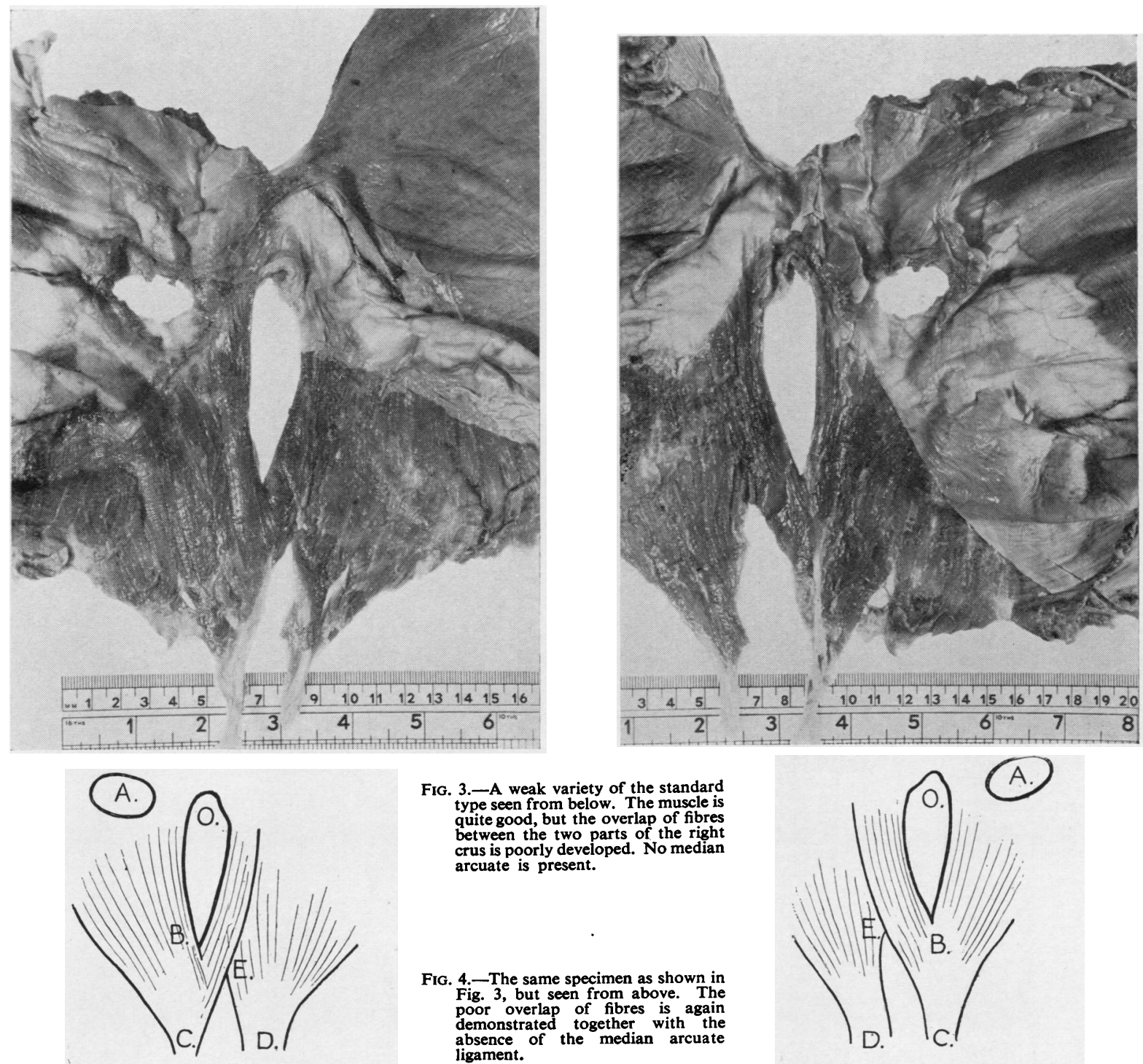
A. ORIFICE FOR INFERIOR VENA CAVA
B. OVERLAPPING FIBRES OF RT. CRUS
C. RT. CRUS
D. LT. CRUS
E. MEDIAN ARCUATE LIGA- MENT
O. OESOPHAGEAL ORIFICE

FIG. 3.-A weak variety of the standard type seen from below. The muscle is quite good, but the overlap of fibres between the two parts of the right crus is poorly develope

Fig. 4.-The same specimen as shown in Fig. 3, but seen from above. The poor overlap of fibres is again absence of the median arcuate ligament.

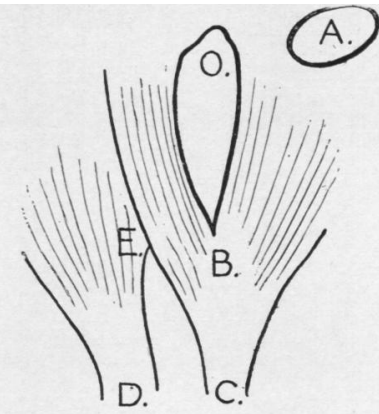

A. ORIFICE FOR INFERIOR VENA CAVA

B. OVERLAPPING FIBRES OF RT. CRUS

C. RT. CRUS

D. LT. CRUS

E. MEDIAN ARCUATE LIGAMENT

O. OESOPHAGEAL ORIFICE

Fig. 3

Fig. 4 

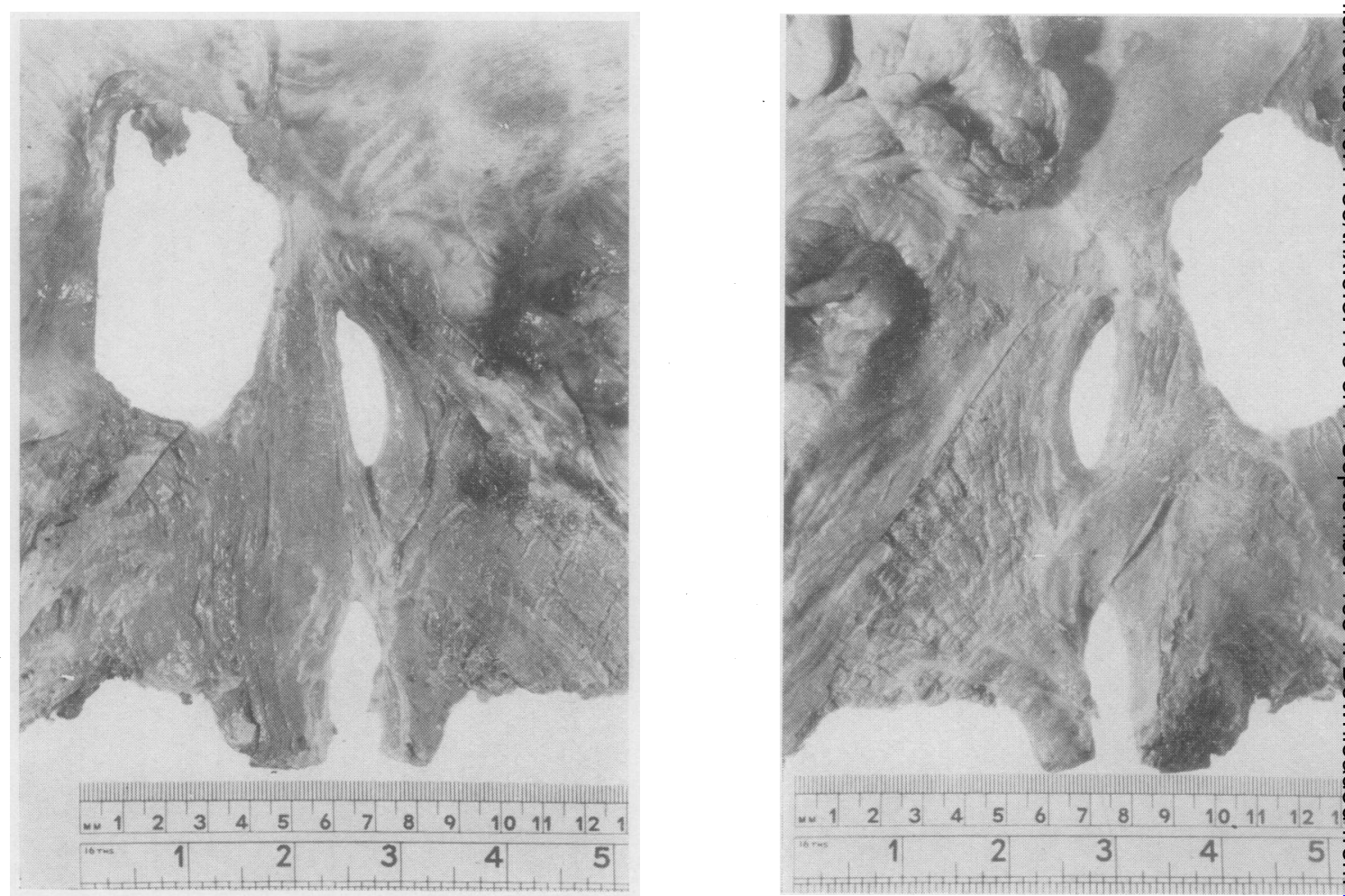

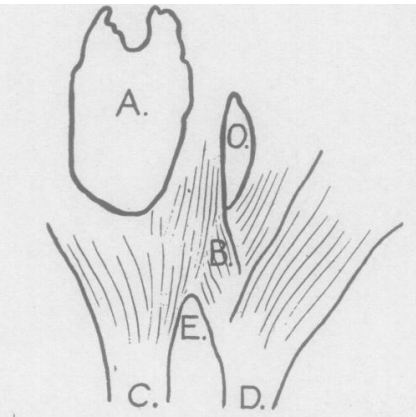

A. ORIFICE FOR INFERIOR VENA CAVA

B. OVERLAPPING FIBRES OF RT. CRUS

C. RT. CRUS

D. LT. CRUS

E. MEDIAN ARCUATE LIGAMENT

O. OESOPHAGEAL ORIFICE
FIG. 5.-Under-surface of a diaphragm showing a stage 1 shift to the left.
A strong median arcuate ligament is A strong median arcuate ligament is for the right of the oesophageal orifice arise from this ligament to the left of the mid-line. The left crus is separate from these fibres and plays no part in forming the oesophageal orifice.

FIG. 6.-Upper surface of same specimen as in Fig. 5. A muscle sheet is seen passing from the left crus to the region of the orifice of the inferior vena cava. (Low, type 2.)

Fig. 5

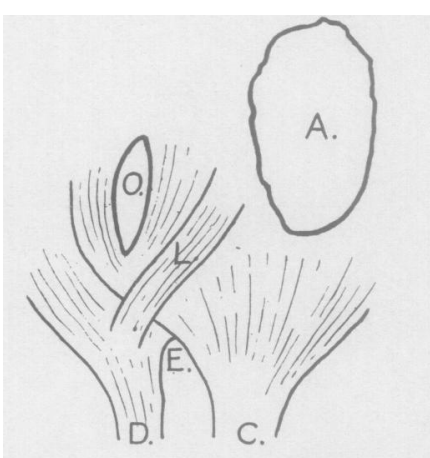

A. ORIFICE FOR INFERIOR VENA CAVA

C. RT. CRUS

D. LT. CRUS

E. MEDIAN ARCUATE LIGAMENT

O. OESOPHAGEAL ORIFICE

L. LOW TYPE 2. MUSCLE 

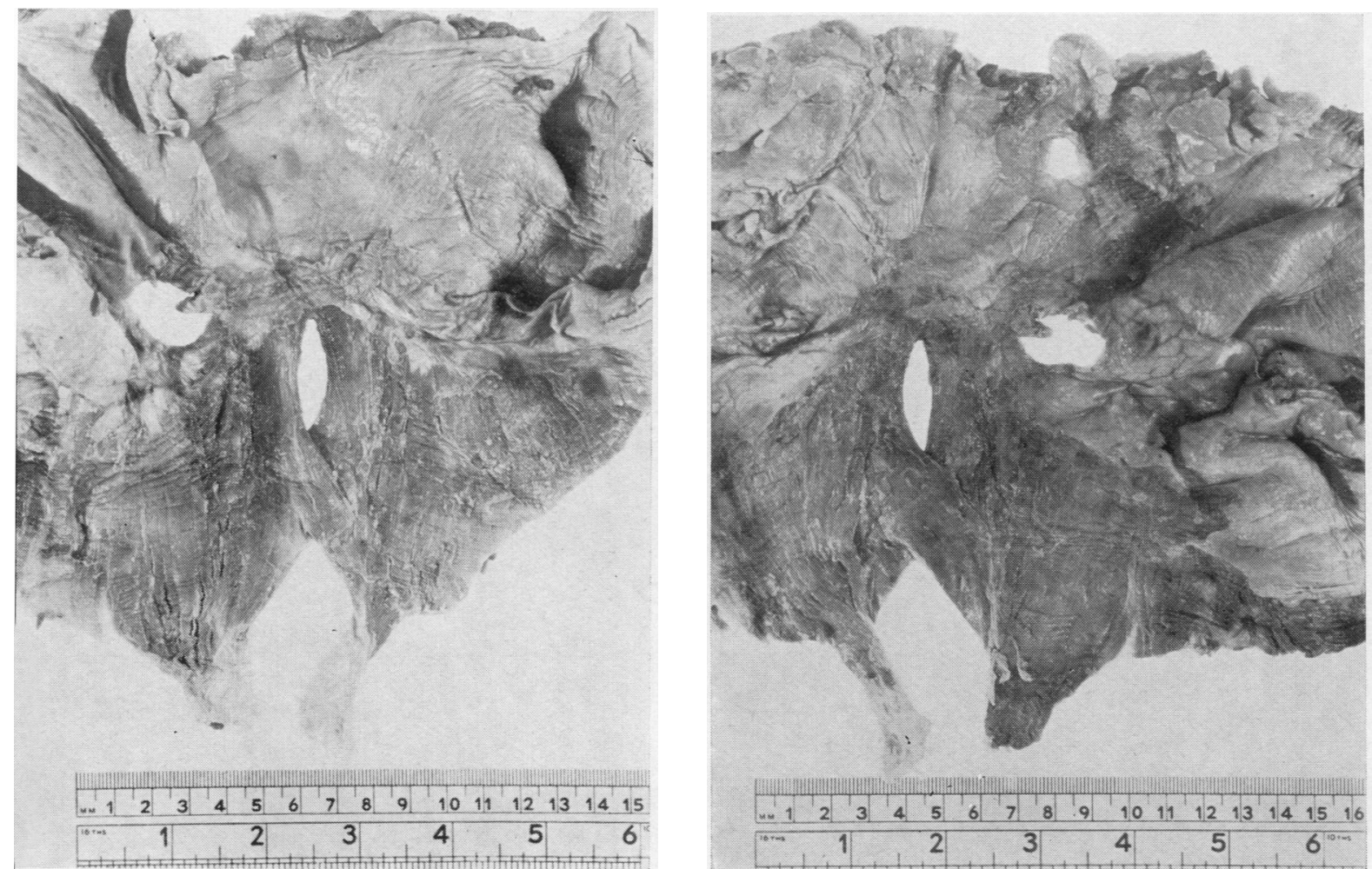

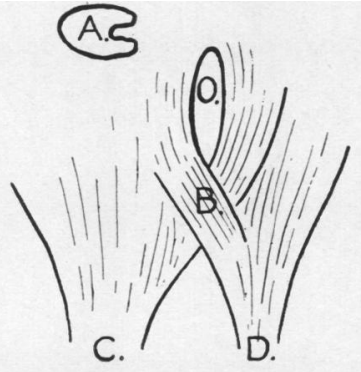
A. ORIFICE FOR INFERIOR VENA CAVA
B. OVERLAPPING FIBRES
FROM LT. CRUS
C. RT. CRUS
D. LT. CRUS
E. MEDIAN ARCUATE LIGA- MENT
O. OESOPHAGEAL ORIFICE

FIG. 7-Under-surface of a diaphragm showing a stage 2 shift to the left of marked degree. The band of fibres on the right side of the oesophagus arises wholly from the left crus and crosses underneath, in scissor fashion; a corresponding band from the right crus going to the left of the oesophageal orifice. The median arcuate ligament is absent.

FIG. 8.-This is the same specimen as seen in Fig. 7 shown from above. The complete cross-over in scissorlike fashion is shown. No median arcuate is present.

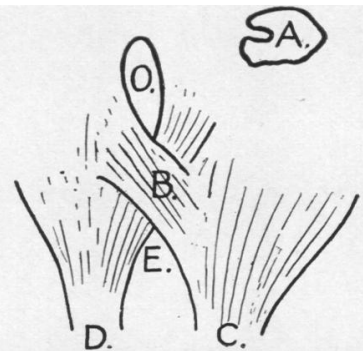

A. ORIFICE FOR INFERIOR VENA CAVA

B. OVERLAPPING FIBRES

FROM RT. CRUS

C. RT. CRUS

D. LT. CRUS

E. MEDIAN ARCUATE LIGAMENT

O. OESOPHAGEAL ORIFICE

Fig. 7

Fig. 8 

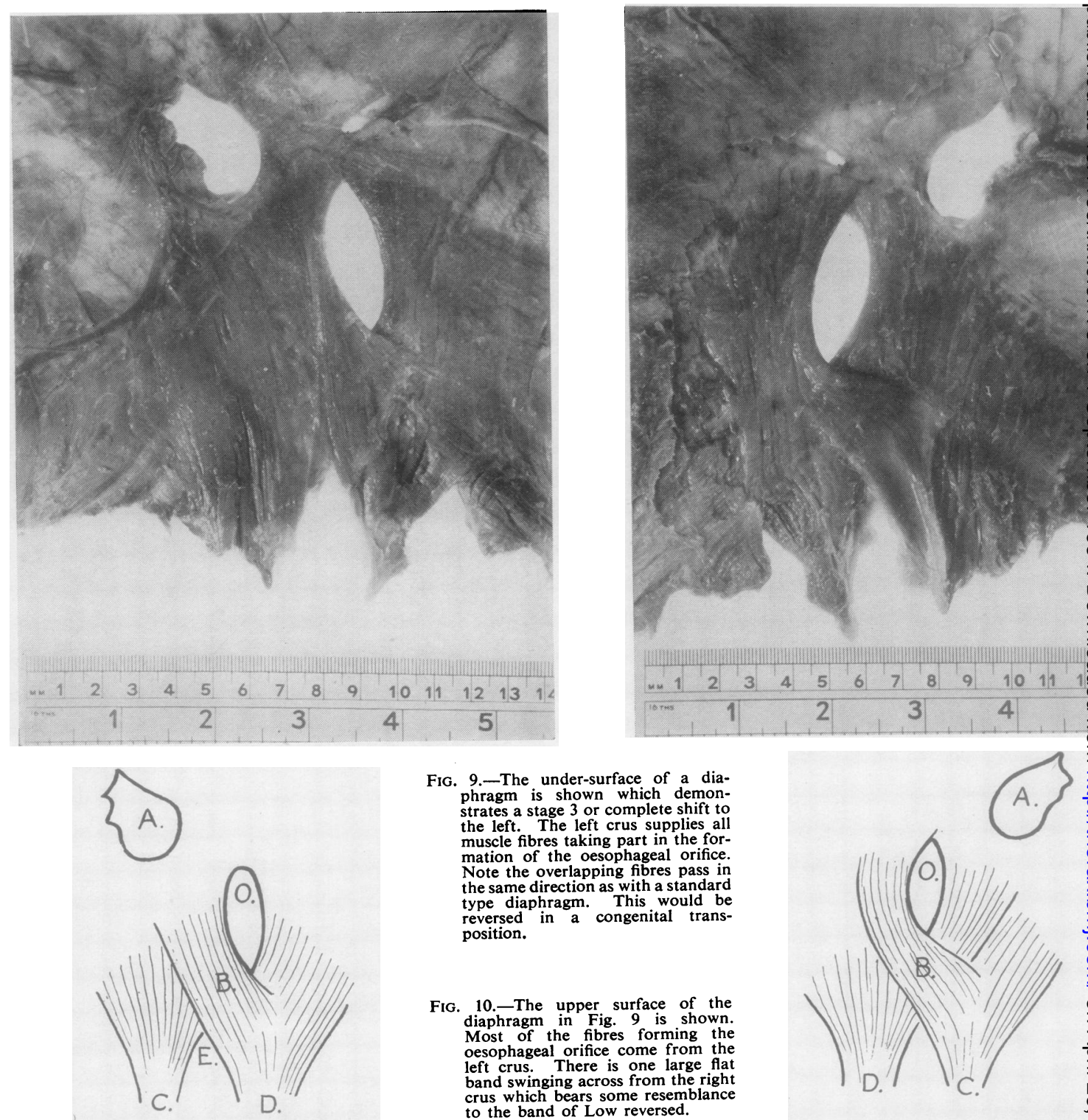
Fig. 9.-The under-surface of a dia- phragm is shown which demon- strates a stage 3 or complete shift to the left. The left crus supplies all the left. muscle fion of the oesophageal orifice. mation of the oesophageal orifice.
Note the overlapping fibres pass in the same direction as with a standard type diaphragm. This would be reversed in a congenital trans- position.

FIG, 10.-The upper surface of the diaphragm in Fig. 9 is shown. Most of the fibres forming the oesophageal orifice come from the left crus. There is one large flat band swinging across from the right crus which bears some resemblance to the band of Low reversed.
A. ORIFICE FOR INFERIOR
VENA CAVA
B. OVERLAPPING FIBRES OF LT. CRUS
C. RT. CRUS
D. LT. CRUS
E. MEDIAN ARCUATE L!GA- MENT
O. OESOPHAGEAL ORIFICE

Fig. 9

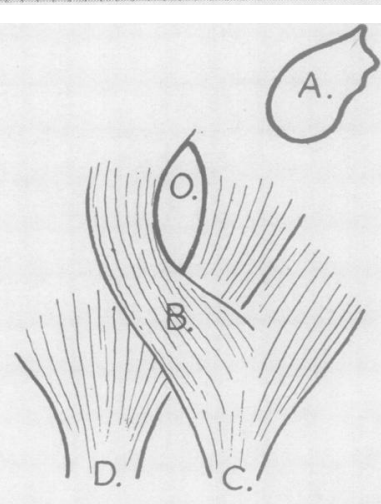

A. ORIFICE FOR INFERIO VENA CAVA

B. OVERLAPPING FIBRES OJ LT. CRUS

C. RT. CRUS

D. LT. CRUS

E. MEDIAN ARCUATE LIG MENT

O. OESOPHAGEAL ORIFICE

Fig. 10 


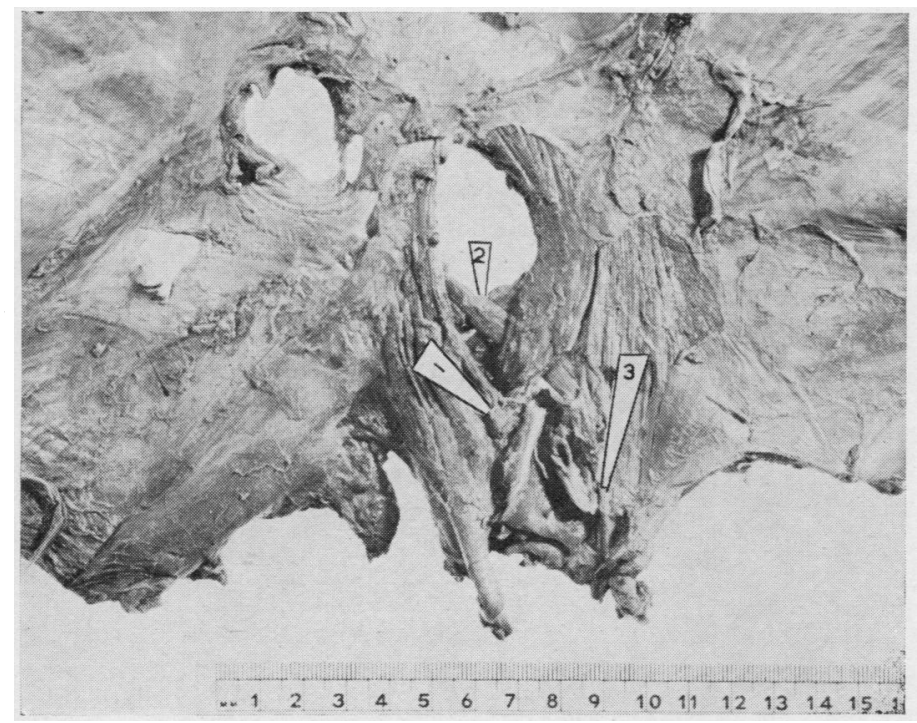

Fig. 11.-The under-surface of a diaphragm with overlap of the fibres of the right crus is shown An additional band can be seen passing from the left crus to the region of the inferior vena cava. Low, type 1 .

Fig. 12.-This is the same specimen as seen in Fig. 11, but after the overlapping fibres of the right crus have been turned back. The muscle of Low type 1 can be seen passing in the direction of the inferior vena cava. It can be seen passing into the fibres of the right crus, as depicted in the figure from the paper by Low, Fig. 13.

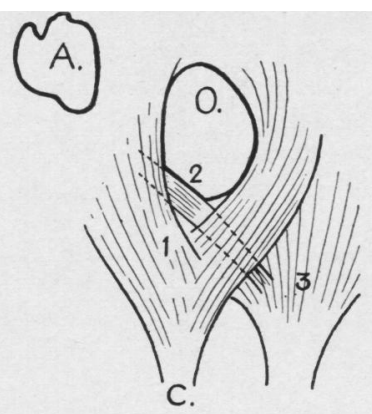

\begin{abstract}
A. ORIFICE FOR INFERIOR VENA CAVA
C. RT. CRUS

O. OESOPHAGEAL ORIFICE

1. OVERLAPPING FIBRES OF RT. CRUS

2. MUSCLE OF LOW. TYPE 1.

3. LT. CRUS
\end{abstract}

Fig. II

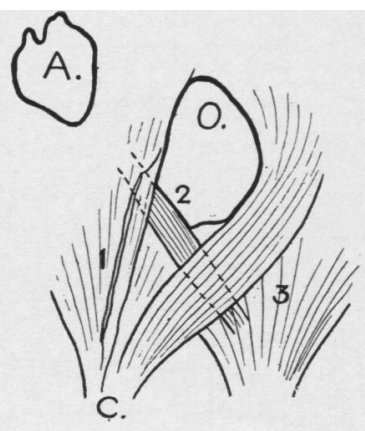
A. ORIFICE FOR INFERIOR VENA CAVA
C. RT. CRUS
O. OESOPHAGEAL ORIFICE
1. OVERLAPPING FIBRES OF RT. CRUS
2. MUSCLE OF LOW TYPE 1.
3. LT, CRUS

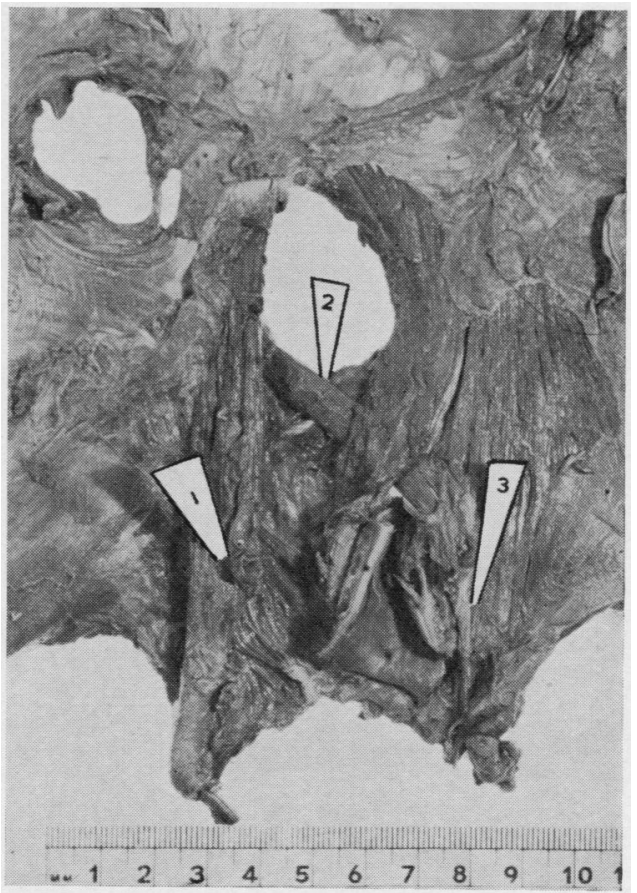

Fig. 12 
from the right crus and passing to the left of the hiatus.

In one case $(2 \%)$ it was the left crus which took the major part in forming the oesophageal hiatus. This is termed a "stage-3 shift" to the left. This case cannot be in the nature of a transposition. Had this been so, the whole pattern would have been a mirror image of the standard with, among other things, the overlap reversed.

\section{Muscle OF LOW: TYPE 1}

Low (1907) described a muscle band about $4 \mathrm{~mm}$. broad extending from the medial aspect of the left crus. This small bundle crossed over in front of the aorta above the level of the coeliac axis and passed obliquely through the fibres of the right crus. Eventually he traced it to the region of the orifice for the inferior vena cava. He found this in four of the 25 cases he examined. It was not found in any of the 50 dissections used for this classification, but it was present in one of the 14 previous dissections. It is shown in Figs. 11 and 12 and the original diagram of Low is reproduced in Fig. 13. It is referred to as a Low muscle type 1 , to distinguish it from a more frequent but rather different band.

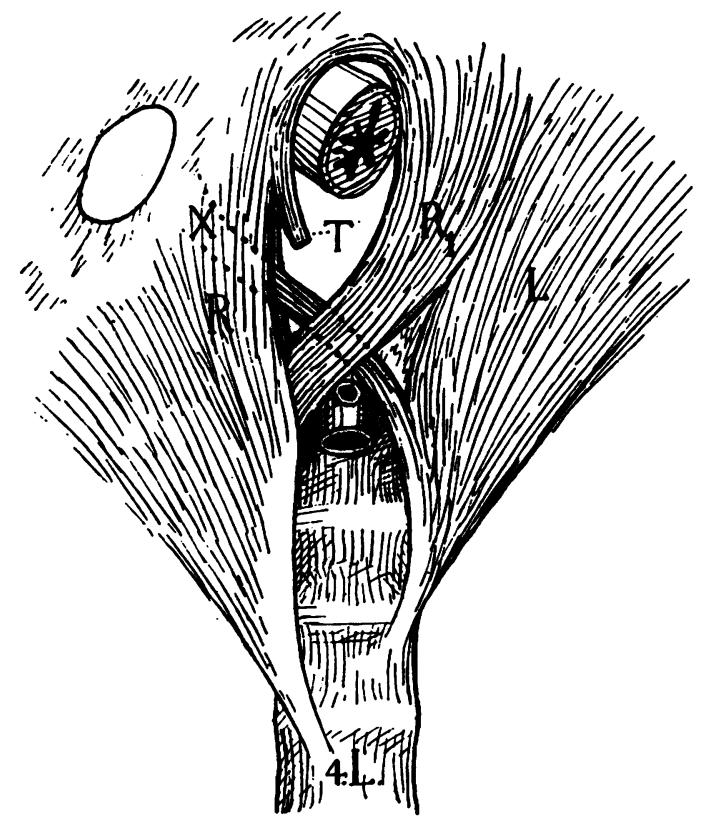

Crura in an adult male.

Fig. 13. - This diagram is taken from the paper by Low and shows a similar arrangement to the specimen illustrated in Figs. 11 and 12. A band from the left crus passes over to the region of the orifice for the inferior vena cava and passes through the substance of the right half of the right crus.
MUSCLE OF LOW: TYPE 2

This was found in $34 \%$ of cases. It is only visible from the upper surface of the diaphragm (Fig. 6F and passes from the left crus in the direction of the orifice of the inferior vena cava, as in the type कै muscle. It is wider and flatter than the muscles noted by Low and is usually $10-16 \mathrm{~mm}$. wide. A.t its fibres are on the upper surface of the diaphragmu and none pass between the fibres of the right crus as Low described. It is to be noted that none of the fibres or either of these muscles take any direct pare in the formation of the oesophageal hiatus.

\section{TRANSVERSE INTERTENDINOUS MUSCLE}

There is yet another distribution of muscle fibre $\vec{\delta}$ in this area which in no way conforms with any of the anatomy previously described. This muscle band is shown in Figs. 14 and 15. It lies on th superior surface of the diaphragm and passeg transversely behind the oesophageal orifice. Eack end gains attachment to the central tendon. Aparo from the specimen shown in Fig. 15, it occurred in $8 \%$ of the 50 specially dissected diaphragms.

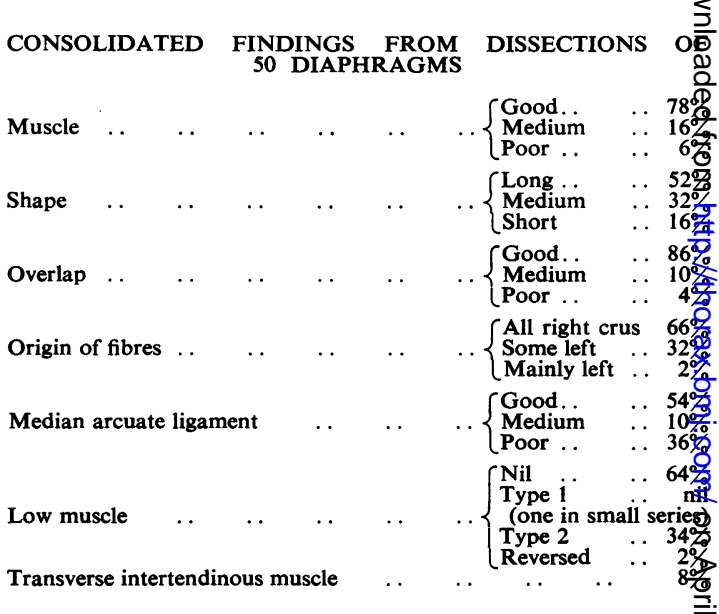

\section{COMMENT ON CONSOLIDATED FINDINGS}

Reference is made to the quality and length of the muscle, and this will be considered further in the section dealing with the deductions from these observations.

One case which is shown in Fig. 10 is classed a having a reversed muscle of Low. This is not absolutely accurate, as the fibres in this muscle which arise from the right crus take part in the formation of the oesophageal orifice. This specime? has no exact place in the classification presented, buo is included here for completeness. 

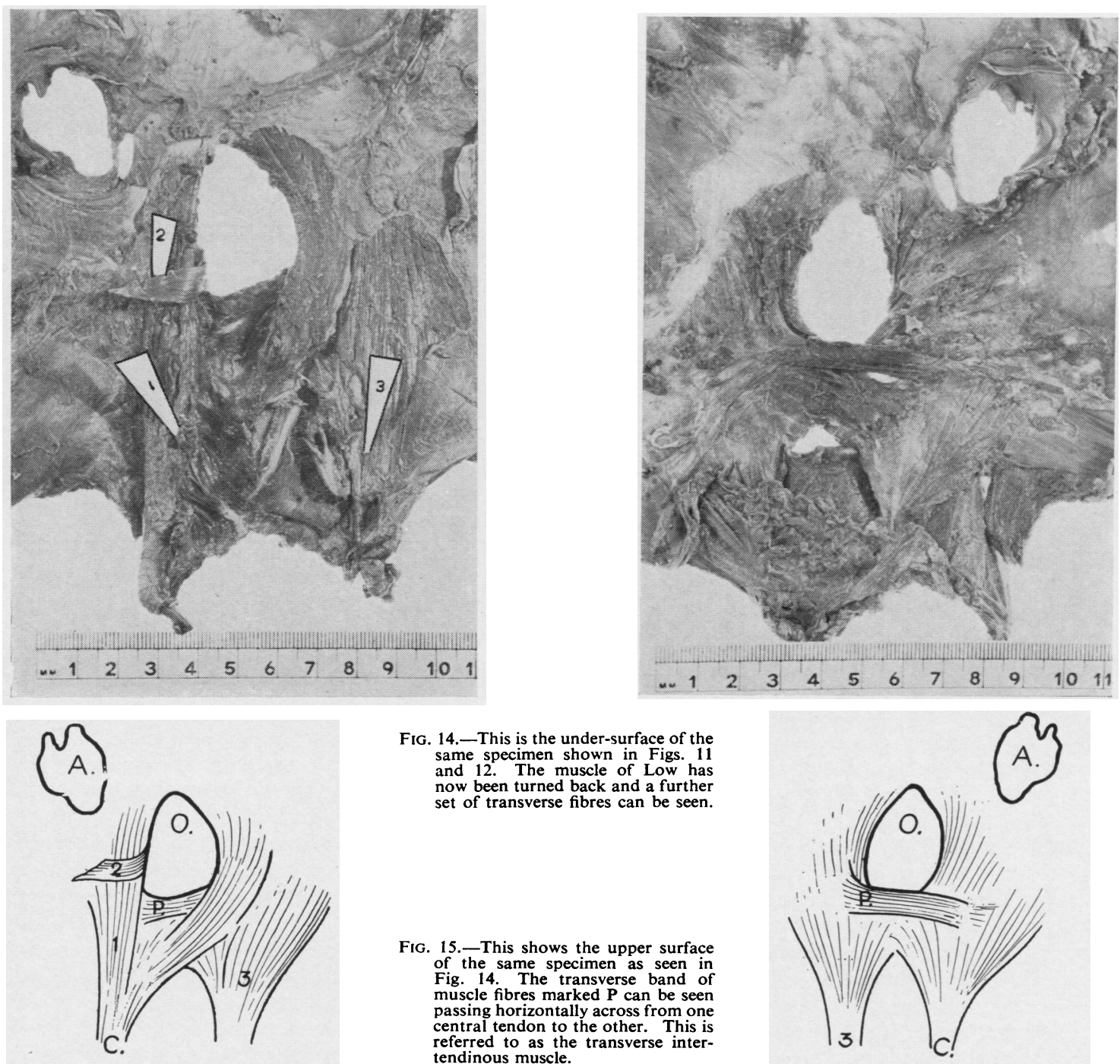

FIG. 14.-This is the under-surface of the same specimen shown in Figs. 11 and 12. The muscle of Low has now been turned back and a further
set of transverse fibres can be seen.
A. ORंIFICE FOR INFERIOR VENA CAVA
C. RT. CRUS
O. OESOPHAGEAL ORIFICE
P. TRANSVERSE INTERTEN- DINOUS MUSCLE
I. OVERLAPPING FIBRES OF RT. CRUS
2. MUSCLE OF LOW. TYPE I 3. LT. CRUS

FIG. 15.-This shows the upper surface of the same specimen as seen in Fig. 14. The transverse band of muscle fibres marked $P$ can be seen passing horizontally across from one central tendon to the other. This is referred to as the transverse intertendinous muscle.

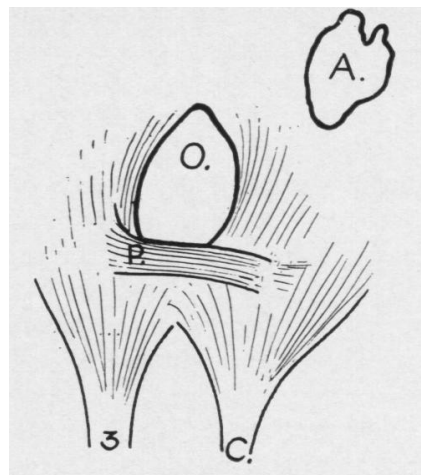
A. ORIFICE FOR INFERIOR VENA CAVA
C. RT. CRUS
O. OESOPHAGEAL ORIFICE
P. TRANSVERSE INTERTEN- DINOUS MUSCLE
3. LT. CRUS

Fig. 14

Fig. 15 


\section{Deductions from Anatomical Studies}

It seems clear from the study of these specimens that the muscle around the oesophageal hiatus is distributed in two ways. There are longitudinal bands stretching from the crura to the central tendon and there are oblique and crossing muscle bands. If it were not for the longitudinal muscle fibres the descent of the rest of the diaphragm would tend to make wider the angle between the oesophagus and the fundus of the stomach. In view of the simultaneous contraction of the longitudinal fibres this angle is kept constant, because the point of their insertion into the central tendon descends to a parallel extent with the rest of the diaphragm. If, as is believed, this angle has an important bearing on preventing regurgitation, its maintenance throughout the respiratory cycle is an essential factor.

During the inspiratory phase regurgitation is more likely because of the more pronounced negative intrapleural pressure, and it would seem reasonable that some additional mechanism should be available to meet this need. It is suggested that the oblique and overlapping arrangements are designed to provide this force. The arrangements referred to include the double-breasted overlap, the various types of shift of muscle fibres to the left, the muscle of Low in its two types and the transverse intertendinous muscle. Some sort of muscle distribution on one or more of these patterns is present in over $95 \%$ of diaphragms, and it is suggested that these fibres produce a scissor effect, tending to close off the lower end of the oesophagus during the inspiratory phase.

The quality and the length of the muscle fibres around the hiatus were also recorded as having a bearing on the strength of the area. It would seem that to some extent shortness of the muscle may be compensated for by more pronounced cross-over fibres, so that the whole area has a square appearance.

In one specimen a hiatus hernia was found. This was unsuspected during life and no symptoms appear to have been produced by it. In view of this, it is interesting to note that the muscle development was good and a well-marked type 2 band of Low was present. It is suggested that the explanation of the absence of symptoms was due to the good muscle which was producing valvular control of the stomach as it passed the powerful hiatus. The strength of the muscle may have been able to prevent gross regurgitation from the stomach below to the stomach above the diaphragm, so that troublesome heartburn did not arise. Further arguments will be put forward about this at a later stage. These have reference to hiatus herniae in children which become asympto- matic and also the operative production of stomache to-stomach control with the object of controllin symptoms. The finding of this hiatus hernia in specimen showing good muscle was at first sigh\$ rather upsetting to the general trend of thought off the subject. However, if the explanation given above is correct, it would seem to strengthen and support. the views expressed.

Post-mortem material on patients suffering symptoms from gastric reflux was not available, bu the opportunity was taken at 18 operations to observeo the position. Uniformly in these cases the crurat muscle would have been classed as medium or weaky in strength, and in all but two cases the overlap was poor.

SUMMARY
The findings from the dissection of 64 diaphragme are described.

The descriptions of Low are confirmed and wit considerable humility elaborated.

The high proportion of cases in which the left crus takes part in the hiatus is noted.

The transverse intertendinous muscle is describe

Certain conclusions about function are draw from these anatomical arrangements.

\section{PART 2: SURGERY OF HIATUS HER N I A}

As has already been stated, the object of the anatomical survey was to gain knowledge which would assist in improving surgical technique for the. control of gastric reflux and the repair of hiatus hernia. Before actually considering the operatiols it would seem appropriate to view the picture on ax broader basis than that of the muscular arrangement at the hiatus only.

Although the term hiatus hernia is used in the title of this paper, the major emphasis is laid on the regurgitation of gastric contents. This is the cause of the main symptoms, and an operatiog can only be considered as satisfactory if this is. prevented or very materially reduced.

\section{Mechanism at the Cardia}

There are certain generally accepted ways if which reflux from the stomach to the oesophagus is prevented. These may be listed under four heading First, the obliquity of the insertion of the oesophagu into the stomach; second, the sling fibres in the stomach; third, the muscle fibres of the right crus and last, the weak sphincter of the lower end of the oesophagus.

The position may be simplified still further b甲 considering that these various muscle masses are 


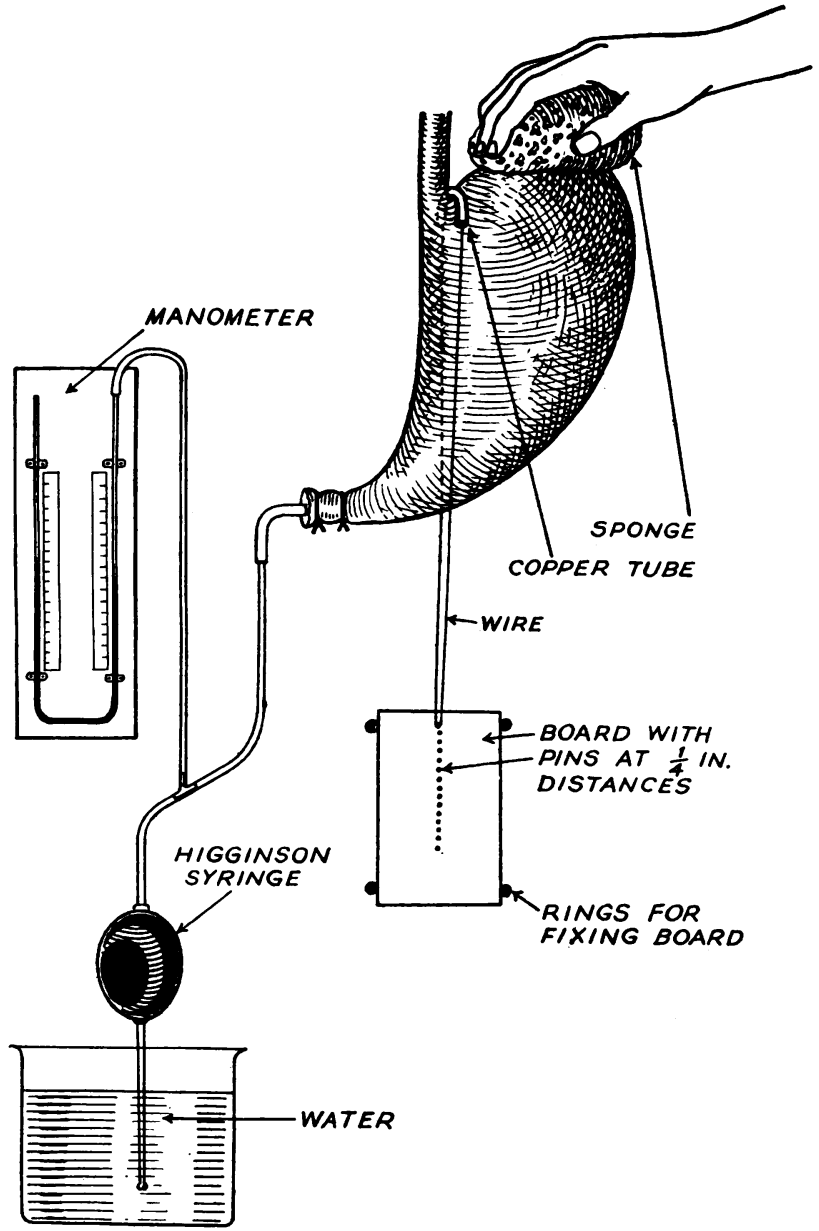

FIG. 16. - This is a diagrammatic plan of the experiments done to demonstrate the effect of increasing the angle between the oesophagus and the stomach. The copper tube over the angle could be lowered by the wire. This wire was looped over a row of pins $\frac{1}{2} \mathrm{~cm}$. apart in a board to give a series of variations in the angle.

serving two functions. Either they are maintaining or increasing the angle of insertion of the oesophagus into the stomach, or they are acting as a sphincter on the lower end of the oesophagus. In the latter case the end is obtained by the weak internal sphincter in the oesophageal wall and by the external sphincter produced by the cross-over action of the right crus, as already described.

The longitudinal pull of the muscle fibres of the right crus and the sling fibres of the stomach produce their effect by increasing the obliquity of the insertion of the oesophagus into the stomach. In this respect Barrett (1952) has demonstrated that the isolated stomach will not allow its contents to regurgitate, provided that this incisura between the two organs is maintained. If, however, the oesophagus is pulled upon so as to obliterate this angle, fluid can readily be expelled from the stomach into the oesophagus. This experiment was repeated and confirmed. Figures were recorded for the pressure necessary to produce regurgitation with varying angles between the oesophagus and stomach. This angle was varied by lowering the copper tube with the wire as shown in Fig. 16. It was anticipated that the pressure necessary would be related directly to the angle. The results obtained showed that free reflux occurred from the full stomach without any increase of the intraluminary pressure until a critical angle was reached. At this point, lowering the copper tube for half an inch produced an abrupt change so that reflux became difficult or impossible to produce. 'The adequacy of the valve action remained constant from this point and it would seem from this that the angle mechanism is a fully effective method of preventing regurgitation.

The process of respiration makes this angle difficult to maintain throughout the cycle. The descent of the dome of the diaphragm tends to open the angle, but its effect is delicately balanced by a parallel contraction of the right crus. It seems important to think of this action of the right crus as maintaining the angle at all times, rather than to consider it as only coming into action in inspiration. Unless this concept is appreciated it might be considered that this angularity prevents regurgitation only in the inspiratory phase.

From the anatomical studies it appears to be the external sphincter produced by the cross-over arrangement of the fibres of the right crus which provides the extra force to prevent regurgitation in the inspiratory phase. It is to be noted here that paralysis of the left phrenic nerve will interfere with this mechanism and may actually aid regurgitation.

It would seem reasonable to accept that reflux from the stomach is controlled by two mechanisms producing either a sphincter action on the lower end of the oesophagus or a narrower angle between the oesophagus and the stomach. In the light of this, all steps in the standard operation should be reviewed to ensure that these two ends are served.

\section{MOULDING THE OPERATION}

Many surgeons have advocated interrupting the left phrenic nerve. As has been shown by Collis, Satchwell, and Abrams (1954), this would have the effect of paralysing the whole of the left half of the diaphragm, including the left half of the right crus. By raising the dome of the diaphragm the incisura 
would be increased, but this advantage would be off-set by weakness at the crus. These opposing factors account for the variability in the results of left phrenic paralysis. A better plan would be to raise the dome of the diaphragm, while leaving the crural fibres to function normally. It must also be remembered that, while the crural fibres pull on the diaphragm from the back, the anterior muscle fibres balance this by contracting in front. Both these actions are necessary for the effective function of the crural muscles.

Selective elevation of the dome of the diaphragm without interfering with the crural action can be effected if the lateral division of the phrenic nerve is divided without cutting the anterior or posterior divisions. This effect is produced by incising the diaphragm obliquely backwards and inwards towards the hiatus as far as the anterior edge of the central tendon. This cut can be embodied into the operation as part of the exposure of the area by an abdomino-thoracic approach, crossing the costal margin at the eighth costal cartilage and opening up the eighth intercostal space.

In dealing with the hiatus itself it is general practice to insert sutures so as to narrow the hole through which the oesophagus passes. This general narrowing does prove effective in the same way as a stricture protects the oesophagus above it. It is an unphysiological approach to the problem and has the disadvantage that there is a group of cases mentioned later in which it is quite ineffective. The success obtained by using this method does seem to prove that symptoms from acid regurgitation are produced by gross reflux and that a proportional improvement may be expected from a proportional narrowing. It is suggested that the plastic repair of the hiatus should be designed to increase the angle between the oesophagus and the stomach. To effect this the point around which the oesophagus and stomach are angulated should be lowered. This can be done by suturing the two parts of the right crus together above and in front of the oesophagus, which in turn is displaced downwards and backwards. It is often possible to increase this angle by as much as an inch.

This point is at direct variance with the Allison (1948) plan adopted by most thoracic surgeons, who place their stitches behind the oesophagus so as to narrow the aperture, while pushing the oesophagus forwards and upwards. This movement of the point of angulation of the stomach on the oesophagus in an upward direction reduces the incisura and must be a definite weakness in the method. The placing of the stitches in the suggested way from above downwards can only be done effectively after dissection of the under-surface of the crural area, and would seem to make it essential that this part of the operation should be done from belove the diaphragm; clearing this area allows downward displacement of the oesophagus with consequen $\overline{0}$ narrowing of the incisura.

After this dissection of the crura and before approximating the pillars of the right crus in fron $\vec{b}$ of the oesophagus, one stitch can be placed behind - . With this in place the stitches from above narrows the opening and aid the external sphincter effect of the right crus. At the same time it is maintaine that the lowering of the point of insertion of the oesophagus into the stomach, thereby narrowing the incisura, is the important step in the operation.

Before performing the plastic repair of the hiatus $\frac{\text { D }}{2}$ the oesophagus and herniated part of the stomachmust be dissected in order to allow the cardia to bef placed in its normal position at the hiatus. In this part of the mobilization it is sometimes an advantage to have access to the chest through the abdomino thoracic approach. Dissection of the mediastinumabove the diaphragm may make this part of the्ध operation easier and may facilitate the difficulf point in deciding whether a given part of the gut ip oesophagus or stomach. As will be put forwark later, over-emphasis should not be given to the positioning of the cardia at the hiatus. Tension on the oesophagus should not be allowed to reduc the effect of the plastic reconstruction of the hiatus so that the increase in the incisura is not obtained? It is felt that it is better to allow a small part of the stomach to be above the hiatus than for this happen. It is not considered that any attempt should be made to elevate the diaphragm and stitch i around the cardia in the chest. This is bound to produce a funnel pointing upwards which witf completely frustrate any plastic reconstruction of the $\overrightarrow{\mathrm{e}}$. normal angle between the oesophagus and the stomach.

Finally, in closing, it is necessary to retain the oesophagus at the hiatus and at the same time fix the fundus under the dome of the left diaphragm sQ as to maintain the incisura to the maximum exten This can be effected by suturing the anterior surface of the fundus to the incision in the diaphragm when this structure is being closed.

In the overall plan for the operation it is als $\stackrel{\omega}{Q}$ necessary to inspect the area adequately, and may include examination of parts within the chest and also laparotomy. This necessity is met by the use of an abdomino-thoracic incision.

\section{Operative TeChNiQue}

After induction of anaesthesia the patient has sand bags placed under the left side so as to raise 
this part about two inches from the table. The left arm is placed at right angles from the side. An incision is made from a point just above the umbilicus and across the costal margin and along the eighth intercostal space. It is carried backwards to the edge of the latissimus dorsi. This muscle is freed from the chest wall by blunt dissection so that the incision in the muscle layers can be carried underneath it. The serratus magnus is incised, and again the muscle is lifted from the chest wall posteriorly beyond the edge of the latissimus dorsi. The area of interdigitation of the serratus and external oblique muscles is lifted from the chest wall and the incision carried forwards through the latter muscle and over the costal margin. The anterior sheath of the rectus is cut and the rectus divided across its fibres.

The eighth intercostal space is then opened and a section of the costal margin removed. This is an important step, as it makes closing easier and prevents a painful area after operation. The abdomen is opened immediately below the costal margin and the incision carried forwards through the posterior sheath of the rectus.

The diaphragm is then incised to the anterior edge of the central tendon but no further. This incision cuts all the divisions of the lateral branch of the left phrenic nerve.

The peritoneum is incised above the hiatus and the left pillar of the right crus is brought into view. To the right of the oesophagus the lesser omentum must be punctured and cut before the right pillar of the right crus can be dissected free from peritoneum.

At this stage a laparotomy can be performed to check for the presence of a peptic ulcer or gallstones. Then a sling is put around the gut at the hiatus. This facilitates the mobilization and identification of the parts.

With this done and the crural fibres cleared down to the coeliac axis, the nature of the overlap of the fibres is noted and a stitch inserted as low down as possible in this area. This stitch attaches together the two limbs of the right crus in the area of their double-breasted overlap.

Attention is now turned to the area above and in front of the oesophagus and the crural fibres are drawn up in a tent fashion while the oesophagus is depressed downwards. A series of sutures is now put in this area between the two limbs of the crus. Care must be taken that these stitches are not inserted too deeply as otherwise the posterior branch of the phrenic nerves on each side may be damaged (Collis, Satchwell, and Abrams, 1954). The lowest of the stitches pulls the limbs of the right crus tightly around the oesophagus and tends to hold it firmly in position.

The incision in the diaphragm is now closed with interrupted thread, which is the same suture material as has been employed in the plastic repair of the crus. The first sutures are put in most posteriorly and with the third and fourth suture the anterior wall of the fundus of the stomach is included. This maintains the cardia in position at the hiatus and ensures that the fundus is applied to the dome of the diaphragm. The chest and abdomen are then closed without drainage, but with care to see that the lung is fully expanded. No special post-operative care is required, and in about half the cases no aspiration of the chest is needed.

\section{SCOPE OF THE OPERATION}

The operation is designed as a plastic repair to prevent acid reflux from the stomach to the oesophagus. Its secondary purpose is to maintain the reduction of the hiatus hernia. It is suitable not only for all types of para-oesophageal and sliding herniae, in which the oesophagus will reach the hiatus, but also for some patients with short oesophagi. When employed in this group the plastic operation produces a valve between the stomach below the diaphragm and the herniated part above. When using the operation for this purpose it is necessary to be certain that the main symptoms are due to regurgitation from the stomach below the diaphragm. There is a clear case for considering this to be so in patients who have a short oesophagus but in whom no oesophagitis is present, but the situation is not so clear when oesophagitis exists.

Aylwin (1953) believes that acid regurgitation in the daytime produces heartburn, but is neutralized so quickly by alkaline saliva that the pepsin cannot act on the oesophageal wall. During sleep, acid in the oesophagus is not neutralized in the same way, and in consequence pepsin activity is possible. After a large series of tests he came to the conclusion that the increase of acid at night was only produced by oxyntic cells within the stomach pouch. These cells are usually few, so that it is only the rather unusual case where oesophagitis from pepsin digestion is possible. On the basis of Aylwin's work, cases with short oesophagus can be divided into two clear groups according to whether or not oesophagitis is present. It can further be considered that when no oesophagitis is present the patient is not suffering from the gastric pouch within the chest. The only exception to this rule would appear to be those cases in which peptic ulceration affects the pouch. This is in the nature of an associated disease rather than directly a result of hiatus hernia, 
and must be excluded before the division of patients is made.

Tests of the same type as those employed by Aylwin have been used in cases in this series, and generally his views have been supported. It has, however, been found that there are sufficient exceptions to call for further investigation, which will be the subject of a later communication. It does, however, seem reasonable to assume that all the cases without oesophagitis are only suffering from reflux from the abdominal part of the stomach and that more elaborate tests will be able to select some cases with oesophagitis who fall into the same group.

This theory was put into practice in three patients with troublesome symptoms from gastric reflux, who had a short oesophagus without any evident oesophagitis. The only alternative seemed an operation of the type of oesophago-jejunostomy with Roux anastomosis as advised by Allison (1951). The patients were elderly and weak and such a procedure was felt to be undesirable. By performing the operation as described, but making no attempt to reduce the hiatus hernia, a valvular mechanism was produced so that no reflux occurred between the stomach in the abdomen and the herniated part. The object was achieved and symptoms relieved.

Belief in this as a practical procedure has been strengthened by the findings of Astley and Carré (1954), who suggest that a similar mechanism operates in infants who spontaneously lose the symptoms of hiatus hernia. Astley has been kind enough to demonstrate some series of radiographs in children passing through the phase of spontaneous cure, and there seems good reason to believe that they develop hiatal control. In this circumstance the oesophagus remains short, but the control at the hiatus prevents gastric reflux from the major part of that organ below the diaphragm to the smaller part above. Once control of gastric reflux has been established they will be difficult to diagnose on barium swallow examination. In these circumstances the nature of the condition can only be found at oesophagoscopy, and may tempt some people to diagnose the condition as a gastric-lined oesophagus. Patients with this arrangement are seen with symptoms in later life, but in view of the frequency of the condition in infants they must represent only a small percentage of the people in whom this abnormality exists. In view of these observations, the application of the operation to a group of patients with short oesophagus would seem to be only a method of applying nature's own cure. By excluding cases with active oesophagitis trouble is unlikely to occur, while by testing the nightly secretions of the oesophagus after operation a check can be made that the $p \mathrm{H}$ is too low for pepsia activity. This has been done in the three patient. mentioned.

\section{FOLLOW-UP}

The follow-up on this small group of 71 persona cases must of necessity be of very limited value, an $\vec{\Phi}$ it is only included to emphasize a few points. It is general experience that symptomatically a very hige proportion of these patients are improved, but the degree of improvement must be a matter open to individual interpretation. As heartburn is the main symptom and is present occasionally in all normat people, it is difficult to see how an absolute assess ment can be reached. Although many patients wh\& still have gastric reflux say that their symptoms are relieved, it is felt that there is a direct relationshife between the amount of reflux and the improvemen of symptoms. The major emphasis has been place $\$$ on the efficacy of the operation to control gastrie reflux, and all patients have been given a standard test. This consisted in laying the patient down ifo the right lateral position after the stomach had beenf filled with barium. While the patient was in thif position he was asked to cough and pressure was applied to his abdomen. The period under reviev? was from January, 1948, to January, 1954. Eack patient was screened on discharge from hospital and at yearly intervals after this. In the case of the abdomino-thoracic approach, some follow-upy periods of as little as three months had to be included, as the operation by this method has only been regularly used since March, 1953.

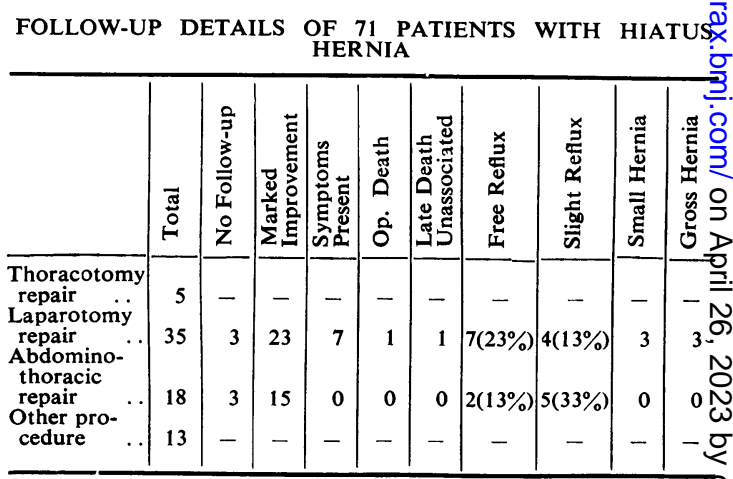

The cases under review fell into two groups? There were 35 patients in whom the operation hado been done through a laparotomy incision and 180 in whom the abdomino-thoracic incision had been used. It might have been appropriate to compares the whole series with other cases treated by the 
thoracic approach, but the lack of tests of gastric reflux in recorded series made this impossible.

The laparotomy series showed a high proportion in which the hernia was unaffected $(9 \%)$ and a further number in which some herniation remained (a further $9 \%$ ). It is felt that these gross defects have been allowed to occur because of the difficulty of obtaining a good view of the operation area through this approach. The position has been corrected in the series done through the abdomino-thoracic incision.

With regard to the question of gastric reflux, both series showed a high figure for cases having some pathological reflux. It was, however, found that gross reflux had become less frequent in the abdomino-thoracic series and that this improvement had run parallel to better symptomatic results. In the two cases with free reflux after operation through the combined approach it was found that the right crus had been paralysed. This was probably due to faulty technique in the early cases done by this route. The incision in the diaphragm had been carried well into the central tendon, and, although this incision was planned to avoid the posterior division of the phrenic nerve, it is thought that this nerve must either have been cut or over-stretched. The presence of this defect can be demonstrated by screening the patient in the left anterior oblique position.

\section{SUMMARY}

It is suggested that the angle of insertion of the oesophagus into the stomach is of great importance in controlling gastric reflux.

The adjuvant effect of the crural muscle as an external sphincter is also stressed.

An operative technique especially designed to promote these two actions is described.

A case has been made for the use of this same operation in one group of cases with short oesophagus.

We wish to acknowledge the help and facilities made available by Professor J. W. Orr, of the Department of Pathology of the Birmingham University, and to Dr. W. Whitelaw and Dr. F. E. D. Griffiths, of Dudley Road Hospital, Birmingham. Our grateful thanks are due to Mr. T. F. Dee, the clinical photographer to the Queen Elizabeth Hospital, Birmingham, for the photographs reproduced here.

\section{REFERENCES}

Allison, P. R. (1948). Thorax, 3, 20. - (1951). Surg. Gynec. Obstet., 92, 419.

Astley, R., and Carré, I. J. (1954). Radiology, 62, 351. Aylwin, J. A. (1953). Thorax, 8, 38.

Barrett, N. R. (1952). Proc. roy. Soc. Med., 45, 279.

Collis, J. L., Satchwell, L. M., and Abrams, L. D. (1954). Thorax, 9, 22.

Harrington, S. W. (1945). Ann. Surg., 122, 546.

- (1948). Surg. Gynec. Obstet., 86, 735.

Low, A. (1907). J. Anat. Physiol., 42, 93.

Sweet, R. H. (1948). New Engl. J. Med., 238, 649. 